\title{
Introduction to the Special Section on Culture and Variants of Sex/ Gender: Bias and Stigma
}

\author{
Heino F. L. Meyer-Bahlburg1
}

Received: 26 November 2014 / Accepted: 21 September 2016/Published online: 29 September 2016

(c) Springer Science+Business Media New York 2016

\begin{abstract}
As a side effect of globalization, the ideological and religious heterogeneity of many local populations is increasing. This trend is particularly noticeable at tertiary-care medical centers serving patients with rare conditions such as somatic intersexuality or gender dysphoria and transgenderism (both with and without somatic intersexuality). This special section is designed to famil iarize clinicians and researchers with culture-associated gender bias and stigma that may influence attitudes to individuals with somatic or behavioral gender atypicalities.
\end{abstract}

Keywords Gender bias · Stigma $\cdot$ Intersexuality ·

Transgenderism $\cdot$ Culture $\cdot$ Islam

Reproduction in all mammalian species, including humans, is sexually organized, i.e., requires the two sexes, male and female. In line with this principle, human societies traditionally have adhered to a binary system of gender, because the long-term survival of the individual, the family, the clan, or the tribe used to depend on reproductive success. Those few members of a society who in terms of body, behavior, and/or identity do not fit into that binary system are accorded a special status, usually of inferior rank and associated with varying degrees of social stigma, sometimes to the degree of frank rejection or even extermination, as illustrated by case reports from the second century CE Roman Empire by Phlegon, a Greek writer at the court of the emperor Hadrian (Hansen, 1996). Very occasionally, the special status may be somewhat exalted, as seems to have been the situation of certain hermaphrodites in ancient

Heino F. L. Meyer-Bahlburg

meyerb@nyspi.columbia.edu

1 New York State Psychiatric Institute/Department of Psychiatry, College of Physicians \& Surgeons of Columbia University, 1051 Riverside Drive, Unit 15, New York, NY 10032, USA
Cyprus, or at least associated with occasional positive special functions, as for instance the performance at wedding ceremonies by the hijras in some regions of India (Nanda, 1998).

Given the importance of physical strength in resource competition and territorial defense, and given the division of labor between the sexes in reproduction, including child-rearing, especially during the child's early years, most traditional societies tend to favor male offspring over female offspring and accord more power to males than to females. The adherence to the binary system of gender and the male gender bias are also codified in the traditional religious systems and their rules of conduct, especially in the religions of the book, although there remain important variations in gender ideology between and within Judaism, Christianity, and Islam (von Braun, 2016).

In the world of the twentieth and twenty-first century, however, both the reliance on muscle power and the importance of reproduction for survival are rapidly diminishing. As a consequence, the traditional division of labor between the genders is fading and, therewith, also the traditionally compelling arguments for a binary system of gender (Meyer-Bahlburg, 2010). As a consequence, full human rights are increasingly demanded by, and gradually accorded to, both genders and, more slowly, also to those minorities who do not fit the traditional gender categories.

Yet, there are tremendous gender-relevant variations in resource status and structural and ideological makeup between societies as well as between subgroups and subcultures within a given society. Recently, grading systems have been developed to characterize such variations. Particularly well known is the Global Gender Gap Index (GGGI), developed by the World Economic Forum. The GGGI is based on the combination of four indicators that are assessed separately by gender for each country, while controlling for the country's economic-developmental level: (a) economic participation and opportunity, (b) educational attainment, (c) health and survival, and (d) political empowerment. The 2015 GGGI ranked 145 countries for 
which sufficient data were available from rank \#1 (smallest gap between genders) to 145 (largest gap), with men usually being in a better position than women. Top ranks were obtained by the Scandinavian countries (\#1 Iceland, \#2 Norway, \#3 Finland), lowest ranks by Syria \#143, Pakistan \#144, and Yemen \#145. The USA was placed on \#28, India \#108, Malaysia \#111, and Egypt \#136 (World Economic Forum, 2015, Table 3, p. 8).

A particularly stark aspect of gender bias in some countries with large gender gaps is the increasing use of diagnostic or visualization methods that permit the determination of the sex of a fetus in utero and is often followed by the termination of pregnancies involving a female fetus (Hvistendahl, 2011; Sen, 2013). In China and India, and especially in certain regions within those countries, this has resulted in highly skewed sex ratios of newborns favoring males, with the ensuing later scarcity of female partners for family formation, sexuality, and reproduction.

Variations in the rigidity/flexibility of the binary sex system as well as in the gender bias between countries and subcultures are associated with major differences in gender socialization in childhood (Kapadia \& Gala, 2015). Gender ideologies can also be expected to influence the parental reaction to newborns with genital ambiguity and, thereby, their clinical management, as well as the attitudes to older individuals (with or without somatic intersexuality) who develop gender dysphoria or desire to change their gender. Globalization adds to these challenges for both clinicians and researchers. In the course of expanding globalization, ever larger numbers of people migrate between and across continents. This includes especially people from resource-poor regions, who often rely on subsistence agriculture and grow up with traditional conservative gender ideologies, and now relocate into comparatively well-off urban centers. Consequently, the local heterogeneity of gender ideologies may increase. In addition, people of high socioeconomic background travel long distances to obtain specialized medical care in centers of excellence with advanced diagnostic and treatment options. These facts make it important that the diverse professionals who conduct research in this area or provide medical, mental-health, and social services to patients with somatic intersexuality or non-intersex transgenderism and to their parents and families become familiar with the diverse cultural and subcultural contexts affecting gender development and gender-related decision-making. Such considerations prompted the development of the special section presented here.

The idea emerged from a symposium on "Gender Bias and Social Stigma and the Clinical Management of DSD" that was convened by this author at the meeting of the International Society for Hypospadias and Intersex in Lucknow, India, November 22-24, 2013. The symposium's speakers included three clinician-specialists performing both clinical work with and research on patients with intersexuality and/or transgenderism: a urologic surgeon from Cairo, Egypt, an endocrinologist (A. C. Ammini) from New Delhi, India, and a psychologist (this author) from New York City. As the surgeon from Cairo was unable to participate in the preparation of manuscripts for publication, another intersex specialist from Cairo, an endocrinologist (I. Mazen), could be persuaded to join the team. In addition, the gynecologist A. Zainuddin, an intersex specialist from Malaysia, who had presented an important related lecture at another symposium of the Lucknow meeting, agreed to contribute an article. We mourn the passing of Professor Ammini in the course of the preparation of her manuscript, which was completed by other members of her team.

By design, the authors of this special section represent countries differing in cultural traditions and especially in the dominant religions. When working with individuals from varied cultural and religious backgrounds, one becomes immediately aware of the strong influence cultural traditions and religious doctrines exert on parents who are trying to adjust to the situation of having a newborn with genital ambiguity and to cope with the associated issues of gender assignment, genital surgery, information disclosure, and their implications for the individual's long-term life course. Similar challenges arise with older transgender individuals (with or without somatic intersexuality). Thus, gaining familiarity with diverse cultural and religious contexts becomes important for the specialist who provides clinical services to patients from varied backgrounds or conducts related research on gender identity and its variants. This special section has been put together to assist clinicians and researchers in beginning to acquire such cultural competency. Especially, the authors from Egypt, India, and Malaysia include among their clientele many patients from very resource-poor regions, who often also adhere to very conservative religion-based gender ideologies.

One of the papers in this special section (Zainuddin \& Mahdy) is devoted specifically to the Islamic perspective on sex/gender and its variants. The reader needs to take into consideration, however, that Islamic doctrine is not monolithic. There are variations within the traditions of the Sunni branch of Islam, which is represented by the authors here, and additional variations within the Shia branch of Islam. One stark example is Iran, a country with a Shia majority, where sex reassignment surgery for (non-DSD) transsexuals is legal, while homosexuality is illegal, as in most Muslim countries, and even punishable by death. Yet, similar to what is happening in the other religions of the book, Judaism and Christianity, there is also a growing evolution of Islamic communities toward tolerance and inclusiveness (Kugle, 2010, 2014; Lind, 2010; Zahed, 2013), especially in the large Islamic diaspora in secular Western democracies. Clinicians and researchers need to be aware of such religious diversity and avoid drawing stereotypic conclusions about a given religious gender ideology.

In clinical settings, such social contexts are obviously highly relevant, when service-providers are planning psychoeducation of parents and, at later ages, patients in preparation for decisions on gender assignment or re-assignment and, possibly, on genital surgery that will have major implications for the future quality of life of the individual. Respectful inquiry about the role of religion in a given family is necessary, and the results need to be taken into 
careful consideration for gender-related joint decision-making. Moreover, clinicians will need to take into account the widespread potential of gender-related stigma. Intersex stigma has generally only been poorly documented and is the primary focus of another article here (Meyer-Bahlburg et al.), but referred to in the other articles as well. Transgender stigma and discrimination have been much better documented (Winter et al., 2016). Increasing awareness of such social contexts is the first step toward the development of comprehensive, culturally competent clinical management policies.

\section{Compliance with Ethical Standards}

Conflict of interest The author declares that he has no conflict of interest.

\section{References}

Hansen, W.(1996). Phlegon of Tralles: Book of marvels. Exeter: University of Exeter Press.

Hvistendahl, M. (2011). Unnatural selection: Choosing boys over girls, and the consequences of a world full of men. New York: Public Affairs/Perseus Books Group.

Kapadia, S., \& Gala, J. (2015). Gender across cultures: Sex and socialization in childhood. In L. A. Jensen (Ed.), The Oxford handbook of human development and culture: An interdisciplinary perspective (pp. 307-324). Oxford: Oxford University Press.

Kugle, S. S. A.-H. (2010). Homosexuality in Islam: Critical reflection on gay, lesbian, and transgender Muslims. Oxford: Oneworld.

Kugle, S. S. A.-H. (2014). Living out Islam: Voices of gay, lesbian, and transgender Muslims. New York: NYU Press.

Lind, A. (Ed.). (2010). Development, sexual rights and global governance. New York: Routledge/Taylor \& Francis.

Meyer-Bahlburg, H. F. L. (2010). Die Zweiheit im Geschlecht? [Duality in sex/gender?]. Sexuologie, 17, 173-177.

Nanda, S. (1998). Neither man nor woman: The hijras of India (2nd ed.). Belmont, CA: Wadsworth Publishing.

Sen, A. (2013). India's women: The mixed truth. New York Review of Books, $L X(15), 24,26-27$.

von Braun, C. (2016). Die symbolische Geschlechterordnung in den drei Religionen des Buches-Säkularisierung und Post-Sexualität [The symbolic gender order in the three religions of the booksecularization and post-sexuality]. Sexuologie, 23, 39-47.

Winter, S., Diamond, M., Green, J., Karasic, D., Reed, T., Whittle, S., et al. (2016). Transgender people: Health at the margins of society. Lancet, 388, 390-400.

World Economic Forum. (2015). The Global Gender Gap Report 2015. Retrieved from http://www3.weforum.org/docs/GGGR2015/cover. pdf.

Zahed, L.-M. (2013). Queer Muslim marriage: Struggle of a gay couple's true life story towards inclusivity and Tawheed within Islam. Seattle, WA: CreateSpace Independent Publishing Platform. 